\title{
ANALYSIS OF GROUND THERMAL CONTROL SYSTEMS FOR SOLAR PHOTOVOLTAIC PERFORMANCE ENHANCEMENT
}

\author{
MAYAMEEN N. REDA ${ }^{1}$, MARKUS SPINNLER ${ }^{1}$, HUSSAIN H. AL-KAYIEM ${ }^{2}$ \\ $\&$ THOMAS SATTELMAYER ${ }^{1}$ \\ ${ }^{1}$ Institute of Thermodynamics, Technical University of Munich, Germany \\ ${ }^{2}$ Mechanical Engineering Department, Universiti Teknologi PETRONAS, Malaysia
}

\begin{abstract}
Arid areas are characterized by high solar radiation, which is an advantage for the performance of photovoltaic (PV) panels. However, they are deteriorating by two setbacks from the harsh climate: shallow temperatures during the night, leading to condensation and overheating during the day, leading to reduced efficiency. The paper discusses and resolves the two setbacks in the performance by cooling the panel during the day and heating it during the night using a ground embedded heat exchanger. Experimental and numerical methods are adopted to carry out the investigation. For that, a numerical model was developed and subjected to a series of measurements. Two PV modules have been tested simultaneously; one is with thermal control system and the second without thermal control. A reduction in the PV surface temperature by around $8^{\circ} \mathrm{C}$ can be obtained during the daytime. The same system can rise the PV surface temperature by around $3^{\circ} \mathrm{C}$ more than the temperature at which condensation takes place.
\end{abstract}

Keywords: ground embedded heat exchanger, thermal control, PV/T.

\section{INTRODUCTION}

Photovoltaic panels have the potential to solve much of the world energy demand by effectively converting the sunlight into electricity However, deserts present the most challenging environment for solar panels; there, heat and dust both have a negative impact on performance, durability, and electrical efficiency. Modern commercial solar cells convert solar irradiation into electric power at the relatively low efficiency of around $20 \% \mathrm{PV}$ panel efficiency decreases due to some factors such as high temperature $(0.5 \% / \mathrm{K}$ in average $)$ and light reflection.

Cooling of PV panels can be achieved by many methods. Continuous water film flowing over the frontal surface of the PV module was studied. The temperature on the back surface was reduced by more than $10 \mathrm{~K}$, while the temperature difference between the front and the back surface was around 7-8 K [1], [2]. Another possibility of PV cooling is to cool the panel at its rear surface. This was experimentally investigated, e.g. by Bahaidarah et al. [3], yielding a temperature reduction of $20 \%$, which resulted in an efficiency increase of the PV panel by 9\% [3]. Another study achieved cooling of the PV panel by introducing water trickling configuration on the upper surface of the panel and obtained an increase of about $15 \%$ in system output at peak radiation conditions [4]. Experimental studies are performed to compare the performance of a PV system combined with a cooling system consisting of a thin film of water running on the top surface of the panel. These studies contain the effects of the nominal power of array and system head on the operation of PV system by cooling the PV cells with a thin film of water [5], [6]. A different investigation of front PV surface cooling was performed by using a spray water cooling technique. Results showed that the cell power increased due to the spraying of water [7], [8].

$\mathrm{PV} / \mathrm{T}$ solar systems are beneficial devices which enable the production of electricity and heat, simultaneously [9]. While the cooling of the PV module is needed only during day time, 
condensation of air humidity on PV panels should be avoided under both day and night conditions. This prevents the formation of mud in the presence of dusty winds, which increases maintenance costs and shortens the lifespan [10]. Furthermore, it is evident that mud layers on the panels' surface reduces the transmissivity of the glass layer and thus also PV efficiency. Frequent cleaning leads to scratching the surface, which in the medium term also leads to a drastic decline in efficiency [11].

Using the earth as a heat source or thermal buffer in a heating or cooling system is an attractive application from a thermodynamic point of view. Underground water cooling systems are potentially more efficient than conventional cooling water-to-air systems. Ground horizontal cooling loops are preferred in many situations, due to a consistent temperature since the ground temperature is not different within a specific depth where the surface heat flux does not play any role [12], [13].

Ground heat exchanger (GHEX) cooling systems are operating on concept that at a certain depth, the soil temperature remains almost constant throughout the year and is approximately equal to the mean surrounding temperature over a year [14]. So, the soil can be used as a thermal sink for the cooling of PV panels [15]. In various studies, earth-water heat exchangers (EWHE) and earth-air heat exchangers for air conditioning use water and air as a cooling medium, respectively [12], [14], [16]. The EWHE pipes are buried below the ground to a particular depth, and the inlet of the tubes carries the hot water, which transfers the energy from the high temperature fluid to the soil, thus resulting in a decrease in outlet temperature [16], [17].

The present study deals with the application of a novel thermal control system for PV panels using a GHEX to solve the overheating and mud formation problems. The thermal control system at hand can cool the PV panel during the day and heat it to temperatures above the dew point during the night. The goal of the thermal control strategy is to increase the day PV performance and to mitigate nocturnal dew formation, thus mud formation. The ground heat exchanger system will be studied using an experimentally validated numerical analysis.

\section{EXPERIMENTAL IMPLEMENTATIONS}

The current investigation has been carried out computationally to extend site measurement utilizing a developed experimental Photovoltaic/Thermal (PV/T) setup. The experimental setup was developed in the humid and warm climate conditions at the University of Technology PETRONAS (UTP), Perak, Malaysia. The computational model was created to simulate the experimental case and impose extended boundary conditions to gain more insight on the effectiveness of the proposed idea of integrating the PV/T with underground embedded coil, GHEX.

\subsection{System description}

The experimental setup for the current study, which also forms the basis for the experimental validation of the numerical model, is shown in Fig. 1. The setup has three primary components: modified solar PV/T unit, ground heat exchanger system and measurements system. PV/T panel is equipped with backside cooling container, with water as cooling/heating medium, circulation pump running at controlled discharge for preselected flow rate and piping circuit that connects the circulating water between the ground heat exchanger and the PV/T back tank.

A horizontal copper pipe channel system was used as a ground heat exchanger, which has an inner diameter of $0.015 \mathrm{~m}$, thickness of $0.003 \mathrm{~m}$ and a total length of $22.0 \mathrm{~m}$. The heat exchanger was installed at $0.8 \mathrm{~m}$. A schematic of the setup is depicted in Fig. 2. 


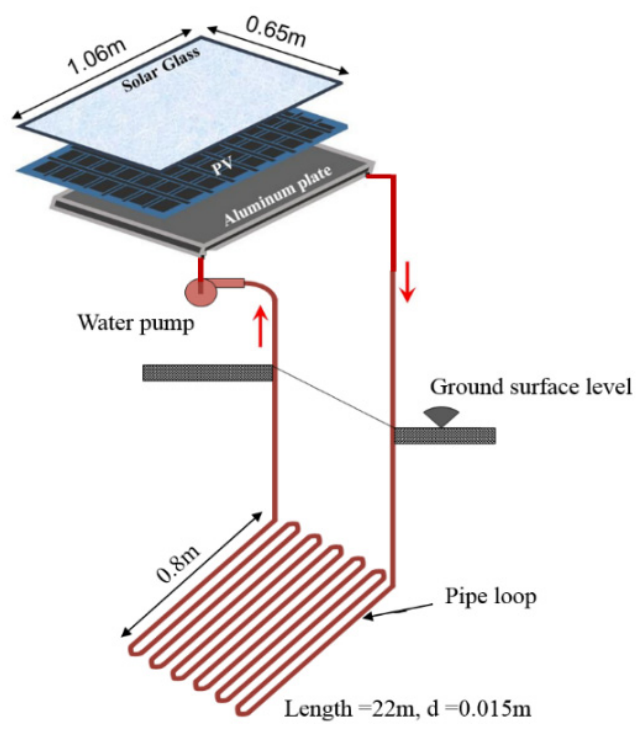

Figure 1: Schematic of the PV thermal control system with backside water cooling and ground heat exchanger.

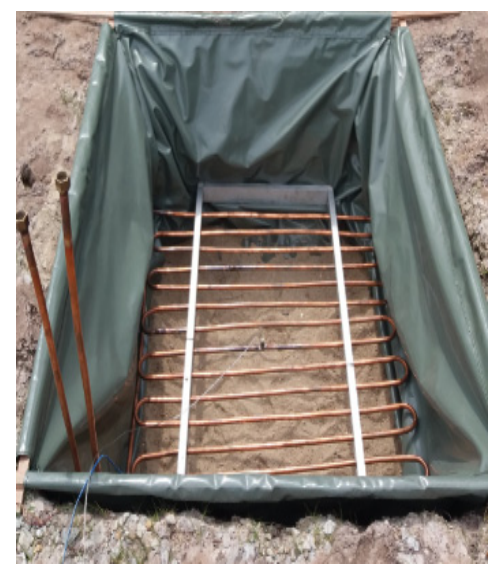

Figure 2: Ground copper pipe loop heat exchanger.

\subsection{Operational principles}

During the day, warm water flowing through the PV backside has been circulated through the GHEX, thus transferring heat to the soil and cool the water. This process increases the soil temperature and store heat to the ground. However, during the night, when water flows through the ground, the storage heat increases the water temperature and heat the PV panel when circulating through the backside panel. The heat storage capacity of the ground is dependent on the thermal properties of the soil [7]. In this study, dry soil with thermal conductivity of $0.2 \mathrm{~W} / \mathrm{m}^{2} \mathrm{~K}$ was considered. 


\section{COMPUTATIONAL PROCEDURE}

The numerical analysis of the present work includes a horizontal ground heat exchanger embedded underground. The simulation considered a block of the ground containing the GHEX. as shown in Fig. 2. The heat exchanger has similar geometries as in the experimental setup. The simulation has been conducted at four different depths, Z, of GHEX installation: $0.5,0.8$, and $1.5 \mathrm{~m}$. The simulation at depth $0.8 \mathrm{~m}$ is utilized for comparison with experimental results and validation.

\subsection{Numerical modelling and meshing criteria}

The ground block selected has $2 \mathrm{~m}$ width $\times 3 \mathrm{~m}$ length $\times 2 \mathrm{~m}$ height. Those ground domain dimensions are large enough compared to the GHEX geometries for assuming adiabatic boundaries. It is almost a far field simulation. The mesh for the copper pipe loops and soil domain is generated using the ANSYS meshing tool. In both domains, a hex-dominant method for reducing the number of cells is used. The cells in the copper pipe loops domain were kept uniform with a cell size of $0.2 \mathrm{~cm}$, which gave enough accuracy of the pipe temperature distribution.

The copper water pipe domain uses cell inflation on the interior of the pipe wall to resolve the boundary layers within the fluid flow. The discretization of these domains provides additional information about heat transfer and fluid flow characteristics within the system. In order to save computation time and because the flow characteristics are relatively simple, a high resolution of these features was not considered. The mesh was concentrated inside the soil pile. The size of the individual mesh elements varied greatly because of the large variation in domain sizes. The size variation of the domains provides challenges in keeping the cell count of the mesh low. The model residual convergence criteria were set to $1 \times 10^{-3}$. The CFD model mesh with the soil domain, the top and bottom of the soil pile, and the copper pipe loops is displayed in Fig. 3.

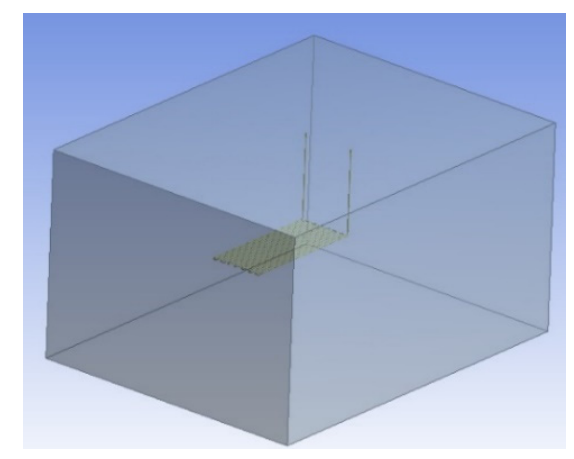

Figure 3: The soil domain and the copper pipe loops domain geometry.

\subsection{Simulation procedure}

The simulation of the current approach was performed numerically using control volume based solver in the commercial software, ANSYS FLUENT. Reynolds-averaged NavierStokes equations have been solved with a Semi-implicit method for pressure-linked equations (SIMPLE algorithm). The realizable $\mathrm{k}-\varepsilon$ turbulence model with enhanced wall treatment and thermal effect option has been adopted. The k- $\varepsilon$ model is appropriate for wall-bounded and 
internal flows with small pressure difference across the flow passage. The main parameters are listed in Table 1. The numerical simulation has been carried out under assumption steadystate conditions. The domain of the problem is discretised as 3D-structured meshing criteria. The heat exchanger was simulated for different operating conditions.

\subsection{Boundary conditions}

For the simulation, the weather data acquired at the solar research site in UTP, Malaysia were used; these considered the interactions of the soil with solar irradiation, wind, and air temperature during the day. The values of the main thermodynamic properties of the materials included in the simulation are shown in Table 2.

The boundary conditions (BC) adopted in the current simulation are mostly same as those used in the experimental investigation. The applied BC conditions used in the simulations are given in Table 3.

Table 1: CFD simulation parameters.

\begin{tabular}{|l|l|}
\hline Parameter & Description \\
\hline Mesh elements & 3D Structured mesh, hex-dominant \\
\hline Numbers of elements/nodes & 228390/289388 \\
\hline Solver & 3D steady-state \\
\hline Pressure velocity coupling & Phase Coupled SIMPLE \\
\hline Turbulence model & Realizable $k-\varepsilon$ \\
\hline
\end{tabular}

Table 2: Material properties involved in the simulations.

\begin{tabular}{|l|c|c|c|}
\hline Property & Pipe (copper) & Ground (soil) & Water \\
\hline Density $\left(\mathrm{kg} / \mathrm{m}^{3}\right)$ & 8,940 & 1,555 & 1,000 \\
\hline Conductivity $(\mathrm{W} /(\mathrm{m} \cdot \mathrm{K}))$ & 250 & 0.2 & 0.6 \\
\hline $\mathrm{Cp}(\mathrm{kJ} /(\mathrm{kg} \cdot \mathrm{K}))$ & 390 & 875 & 4,184 \\
\hline Viscosity $(\mathrm{kg} / \mathrm{m} \cdot \mathrm{s})$ & - & - & 0.001003 \\
\hline
\end{tabular}

Table 3: Boundary conditions adopted in the simulation.

\begin{tabular}{|l|l|}
\hline Parameter & Value \\
\hline Water mass flow rate & $0.02778 \mathrm{~kg} / \mathrm{s}$ \\
\hline Water inlet temperature & According to the transient measured data, on hourly base \\
\hline Soil thermal diffusivity & $1 \times 10^{-6} \mathrm{~m}^{2} / \mathrm{s}$ \\
\hline Depth & $0.5 \mathrm{~m}, 0.8 \mathrm{~m}, 1.0 \mathrm{~m}$ and $1.5 \mathrm{~m}$ \\
\hline
\end{tabular}

\section{RESULTS AND DISCUSSIONS}

The numerical simulation has been carried out at controlled water flow rate of 1.6 LPM. The experimental conditions during the measurement are essential to be identified prior to commencing the discussion of the results. 


\subsection{Experimental verification on the functionality of GHEX}

The performance of the PV panel can be enhanced by incorporating a rear side water cooling system, thereby removing diurnal excess heat from the PV panel and charge it to the ground by GHEX. During the night, this PV thermal control system (PV/T) allows heating the PV panel to temperatures higher than the dew point. Thereby, dew and subsequent mud formation can be mitigated and the ground thermal storage can be conditioned for optimal diurnal operation as a heat sink.

Fig. 4 shows the measured ground temperature distribution for two depths $(0.5 \mathrm{~m}$ and $0.8 \mathrm{~m}$ ). The two curves are almost identical in the early morning hours of the day, while the divergence begins after 11.30 AM until it reaches its maximum value at around 4.30 PM. Two conclusions could be drawn from those measurements. First, it is clear that the soil temperature is almost constant at $0.8 \mathrm{~m}$ depth with slight increase in the afternoon, as the solar radiation with high irradiance and high incidence. Second, the temperature of ground at $0.5 \mathrm{~m}$ depth is not suitable for the installation of the GHEX as it is relatively high and the heat removal from the hot water will be inefficient.

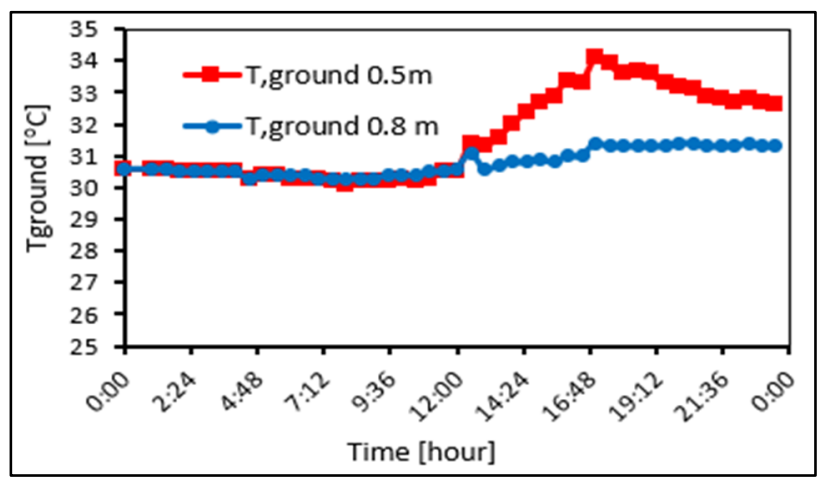

Figure 4: Experiment ground temperature at $0.5 \mathrm{~m}$ and $1 \mathrm{~m}$ depth for 5 th October Malaysia.

Fig. 5 shows the measured temperatures at the surfaces of the PV/T panel and the reference PV panel, and the solar irradiation over a full day in October month. At noontime, from 12.00 PM till 2.30 PM, the system shows near steady-state behaviour. Compared to conventional PV panels, the thermal control system can reduce the PV cell temperature by $8 \mathrm{~K}$. This temperature reduction is enough to keep the PV cell temperature near to the normal operating condition of around $48^{\circ} \mathrm{C}$. During the condensation time (3:30 AM to 7:30 AM), the thermal control system is realized to be able to keep the PV surface temperature above the dew temperature by $2-4^{\circ} \mathrm{C}$. By this thermal control system, the PV efficiency can be increased by $10 \%$, and nocturnal condensation can be avoided.

Compared to conventional PV panels, the thermal control system demonstrated the ability to reduce the PV cell temperature by around $8 \mathrm{~K}$. This temperature reduction, which results from the use of the GHEX, is sufficient to maintain the PV cell temperature close to the normal operating condition of around $48^{\circ} \mathrm{C}$. During the condensation time (3:30 AM to 7:30 AM) the thermal control system by GHEX managed to keep the PV surface temperature above the dew temperature by 2-4 K. By the GHEX thermal control system, the daily PV efficiency can be increased by around $10.0 \%$, and nocturnal condensation can be avoided. 


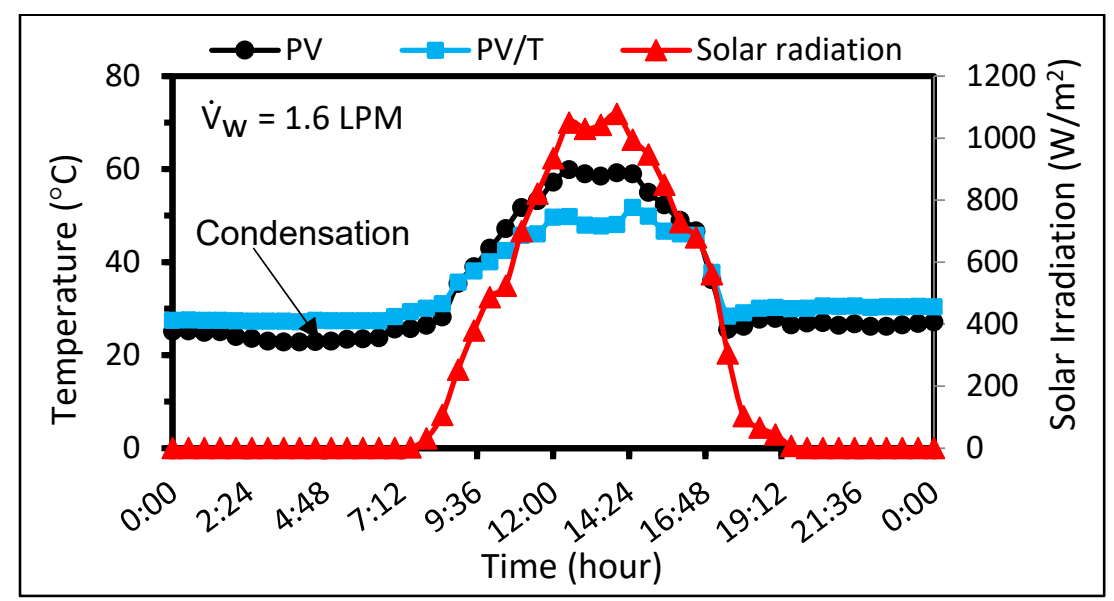

Figure 5: The experimental temperature distribution and the solar irradiation over a day in October for a water flow rate of 1.6 LPM.

\subsection{Numerical analysis}

The numerical procedure developed in this research is aimed to simulate the operational performance of GHEX that is hypothesised to enhance the performance of PV/T system.

\subsubsection{Validation of computational procedure}

Prior to presenting and discussing the numerical results, the computational procedure is to be validated. The validation has been achieved through comparison between the water temperature at outlet of the GHEX as measured experimentally and that predicted numerically by the simulation. The comparison results are shown in Fig. 6.

The short-term behaviour of the fluid outlet temperature was compared as obtained experimentally and numerically during every 1 hour at a depth of $0.8 \mathrm{~m}$. As can be seen in Fig. 6, the maximum difference between the simulation results and experimental data is about

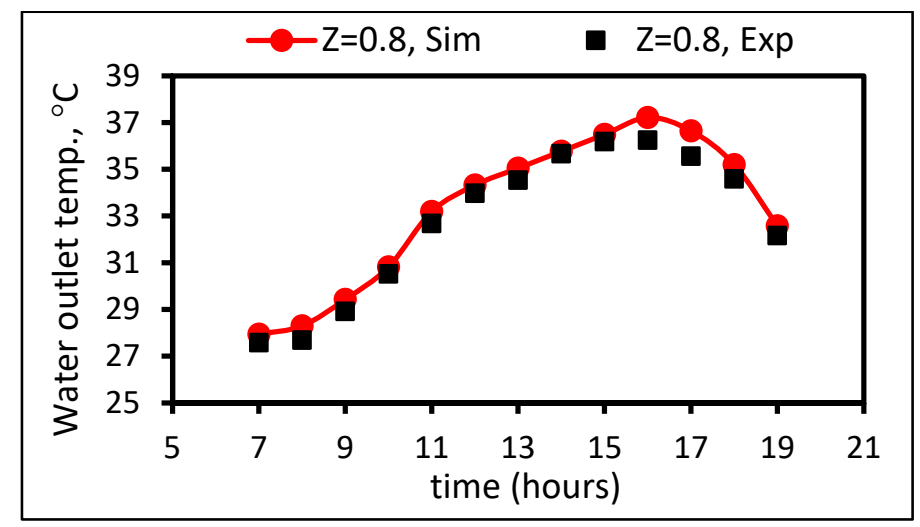

Figure 6: Comparison between the numerical prediction and experimental measurement results of outlet water temperature from the GHEX installed at $0.8 \mathrm{~m}$ depth. 
$3.2 \%$ and $2.2 \%$, respectively. So, it is reasonable to say that the outlet fluid temperature shows reasonable agreement with the experimental data. The numerical model and experimental data matched well in this timeframe, whereas a maximum deviation of $0.6 \mathrm{~K}$ was observed at 5 PM.

\subsubsection{Analysis of ground temperature simulation}

Fig. 7 shows the temperature profiles in the soil pile at two different buried GHEX depths, $0.5 \mathrm{~m}$, and $1.0 \mathrm{~m}$, at $12 \mathrm{PM}$, October 11th. The temperature profiles show that under realistic weather conditions, the soil temperature varies minimally at $1.0 \mathrm{~m}$ depth, whereas temperature is almost constant below a certain depth, around $1.5 \mathrm{~m}$. This is the ideal location for the ground heat exchanger as it was not affected much by the ambient weather conditions. At $1.5 \mathrm{~m}$ depth and below, it is possible to obtain the maximum temperature between circulatory water inside the UGHX and the surroundings.

\subsubsection{Analysis of thermal field in the GHEX}

Fig. 8 displays the heat dissipation in the buried GHEX at $0.8 \mathrm{~m}$ depth, at 12:00 PM. Hot water flows in the GHEX at around $313 \mathrm{~K}$ and leaves at around $308 \mathrm{~K}$. the GHEX managed to reduce the water temperature by around $5^{\circ}$. This demonstrates the correctness of the hypothesis and the proposed technique for reducing the PV surface temperature.

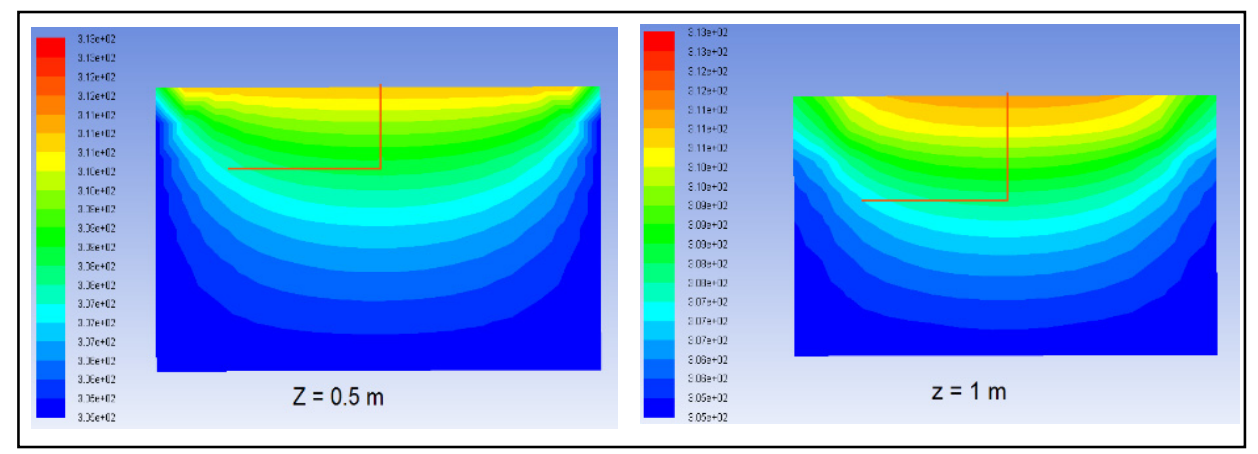

Figure 7: Temperature profile in the soil of the simulation block, considering the presence of the GHEX at 0.5 and $1.0 \mathrm{~m}$ depth.

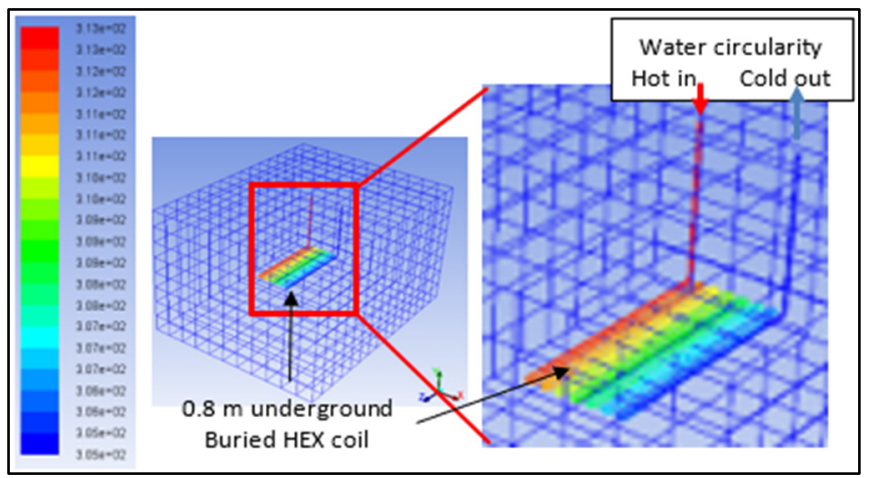

Figure 8: Temperature profile of the GHEX, at $0.8 \mathrm{~m}$ depth, October 11th, $12 \mathrm{PM}$. 


\subsection{Analysis of GHEX performance}

The performance of the ground heat exchanger system is directly related to the difference between the outlet water temperature from the heat exchanger and the soil temperature. In general, the positive value of this difference means heating of water, and the negative value means the cooling of water in the ground, as shown in Fig. 8. The figure also predicts that the ground heat storage system was heating the water before 9:00 AM, whereas, between 9:00 AM to 8:00 PM, the GHEX system was cooling the water.

Fig. 9 shows the water outlet temperature from the GHEX at various times when the GHEX is located at depths of $0.8 \mathrm{~m}, 0.5 \mathrm{~m}$, and $1.5 \mathrm{~m}$. With larger depths of the copper pipe loop, the overall heat transfer area towards the colder soil is also growing. Besides, the water temperature was less affected by the thermal condition of the soil surface for a larger burial depth of the pipe. Therefore, the water outlet temperature decreases with increasing depth.

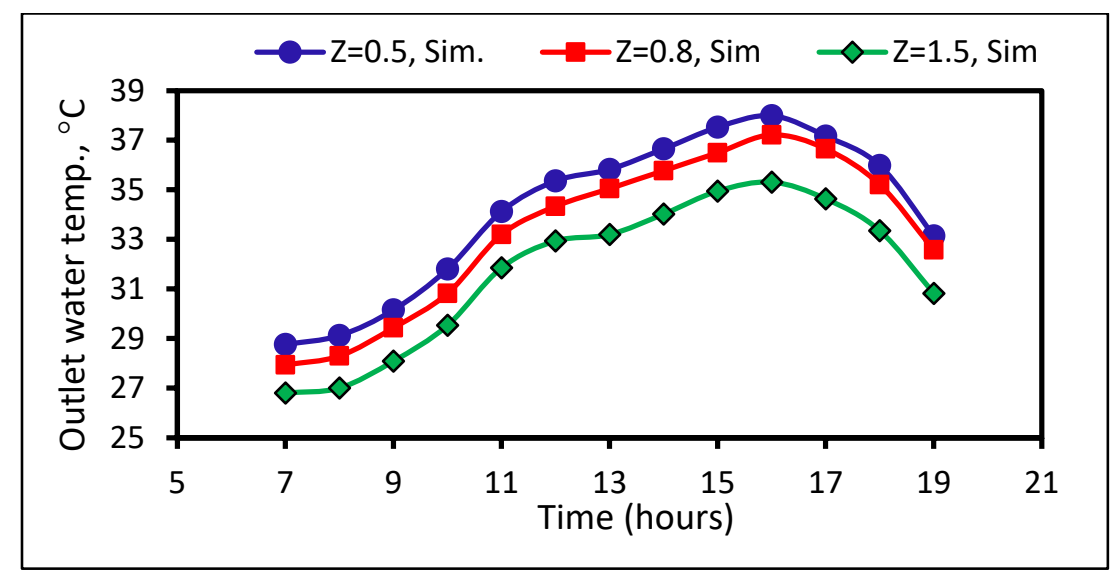

Figure 9: The predicted temperature of water at outlet from the GHEX, from 7:00 AM to 7:00 PM.

\section{CONCLUSIONS}

It is hypothesised that installation of cooling tank, at the back of the PV, connected to ground heat exchanger would enhance the PV/T performance. Experimental and numerical assessment demonstrated the functionality of the method. Results show that the GHEX cools the water in the day and reduces the PV surface temperature by around $8^{\circ} \mathrm{C}$ leading to improved PV efficiency by about $10 \%$. Experimental measurements revealed that the GHEX has contributed in warming up the water in the night and eliminate the vapor condensation on the PV surface.

\section{ACKNOWLEDGEMENT}

The authors acknowledge Universiti Teknologi PETRONAS (UTP), Malaysia for the financial support to carry out the research under research grant YUTP-FRG, CS: 015LC0206. 


\section{REFERENCES}

[1] Dorobanţu, L., Popescu, M., Popescu, C. \& Crăciunescu, A., Experimental assessment of PV panels front water cooling strategy. International Conference on Renewable Energies and Power Quality (ICREPQ'13), Bilbao, Spain, pp. 1009-1012, 2013.

[2] Krauter, S., Increased electrical yield via water flow over the front of photovoltaic panels. Solar Energy Materials and Solar Cells, 82, pp. 131-137, 2004.

[3] Bahaidarah, H., Subhan, A., Gandhidasan, P. \& Rehman, S., Performance evaluation of a PV (photovoltaic) module by back surface water cooling for hot climatic conditions. Energy, 59, pp. 445-453, 2013.

[4] Odeh, S. \& Behnia, M., Improving photovoltaic module efficiency using water cooling. Heat Transfer Engineering, 30, pp. 499-505, 2009.

[5] Hosseini, R., Hosseini, N. \& Khorasanizadeh, H., An experimental study of combining a photovoltaic system with a heating system. World Renewable Energy Congress, Linköping, Sweden, pp. 2993-3000, 2011.

[6] Kordzadeh, A., The effects of nominal power of array and system head on the operation of photovoltaic water pumping set with array surface covered by a film of water. Renewable Energy, 35, pp. 1098-1102, 2010.

[7] Hongbing, C., Xilin, C., Sizhuo, L. \& Sai, C., Experimental study on the energy performance of PV-HP water heating system. Energy Procedia, 75, pp. 294-300, 2015.

[8] Moharram, K.A., Abd-Elhady, M., Kandil, H. \& El-Sherif, H., Enhancing the performance of photovoltaic panels by water cooling. Ain Shams Engineering Journal, 4, pp. 869-877, 2013.

[9] Jakhar, S., Soni, M. \& Gakkhar, N., Performance analysis of photovoltaic panels with earth water heat exchanger cooling. MATEC Web of Conferences, 2016.

[10] Chiasson, A.D., Spitler, J.D., Rees, S.J. \& Smith, M.D., A model for simulating the performance of a shallow pond as a supplemental heat rejecter with closed-loop ground-source heat pump systems. Ashrae Transactions, 106, p. 107, 2000.

[11] Hegazy, A.A., Effect of dust accumulation on solar transmittance through glass covers of plate-type collectors. Renewable Energy, 22(4), pp. 525-540, 2001.

[12] Yusof, T.M., Anuar, S. \& Ibrahim, H., A review of ground heat exchangers for cooling application in the Malaysian climate. Journal of Mechanical Engineering and Sciences, 8, pp. 1426-1439, 2015.

[13] ASHRAE Handbook, American Society of Heating, Refrigeration and AirConditioning Engineers, Inc, 2005.

[14] Bansal, V., Misra, R., Agrawal, G.D. \& Mathur, J., Performance analysis of earthpipe-air heat exchanger for winter heating. Energy and Buildings, 41, pp. 1151-1154, 2009.

[15] Chel, A., Janssens, A. \& De Paepe, M., Thermal performance of a nearly zero energy passive house integrated with the air-air heat exchanger and the earth-water heat exchanger. Energy and Buildings, 96, pp. 53-63, 2015.

[16] T'Joen, C., Liu, L. \& De Paepe, M., Comparison of earth-air and earth-water ground tube heat exchangers for residential application. International Refrigeration and AirConditioning Conference, Purdue University, Herrick Laboratories, 2012.

[17] Chel, A., Janssens, A. \& De Paepe, M., Thermal performance of a nearly zero energy passive house integrated with the air-air heat exchanger and the earth-water heat exchanger. Energy and Buildings, 96, pp. 53-63, 2015. 